\title{
Photoinhibition from chronic herbicide exposure reduces reproductive output of reef-building corals
}

\author{
Neal E. Cantin ${ }^{1,2,3,4}$, Andrew P. Negri ${ }^{3,4, *}$, Bette L. Willis ${ }^{1,2,4}$ \\ ${ }^{1}$ ARC Centre of Excellence for Coral Reef Studies and ${ }^{2}$ School of Marine and Tropical Biology, James Cook University, \\ Townsville, Queensland 4811, Australia \\ ${ }^{3}$ Australian Institute of Marine Science, PMB 3 MC, Townsville, Queensland 4810, Australia \\ ${ }^{4}$ AIMS@JCU, Sir George Fisher Building, James Cook University, Townsville, Queensland 4811, Australia
}

\begin{abstract}
The photosystem II (PSII) herbicide diuron is commonly used within catchments that drain into the Great Barrier Reef lagoon, where it potentially reduces photosynthesis in Symbiodinium, the dinoflagellate symbiont associated with reef corals. Here we examine the importance of energy (carbohydrates) derived from photosynthesis to the gametogenesis of corals following longterm, experimental exposures to diuron. Two broadcast spawning corals, Acropora tenuis and A. valida, and a brooding coral, Pocillopora damicornis, were exposed to 0 (controls), 1.0 (low) and 10 (moderate) $\mathrm{\mu g} \mathrm{l}^{-1}$ diuron treatments for 2 to 3 mo prior to spawning or planulation. Diuron caused photoinhibition in each species, with pulse amplitude modulation (PAM) fluorometery recording consistent declines in effective quantum yields of $20 \%$ at $1.0 \mu \mathrm{g} \mathrm{l}^{-1}$ and $75 \%$ at $10 \mathrm{\mu g} \mathrm{l}^{-1}$ diuron compared to control corals. A. valida and P. damicornis were both sensitive to chronic diuron-induced photoinhibition, becoming severely bleached (loss of Symbiodinium spp. and/or reductions in lightharvesting pigments), especially at $10 \mu \mathrm{g} \mathrm{l}^{-1}$ diuron. At this moderate concentration, A. valida sustained both partial and full colony mortality. A. tenuis was more resistant to these concentrations of diuron, and neither bleached nor sustained partial mortality in any of the treatments. We found 2.5to 5 -fold reductions in total lipid content (coral tissue, oocytes and planulae) for the 3 species in the presence of diuron, indicating significant use of storage lipid to meet nutritional demands under conditions of chronic photoinhibition. Polyp fecundity was reduced by 6 -fold in A. valida and both A. valida and P. damicornis were unable to spawn or planulate following long-term exposures to $10 \mathrm{ug} \mathrm{l}^{-1}$ diuron. This is the first study to investigate the sub-lethal effects of chronic herbicide-induced photoinhibition on symbiotic corals and provides evidence of a link between reduced energy acquisition due to PSII photoinhibition and reduced reproductive output in zooxanthellate corals.
\end{abstract}

KEY WORDS: Coral · Reproduction - Diuron - Photoinhibition · Herbicide · Symbiosis · Photosynthesis $\cdot$ Pigment

\section{INTRODUCTION}

Recent reports highlight the deleterious impacts that pesticides may have on inshore flora and fauna of the Great Barrier Reef (GBR) (Haynes et al. 2000, Jones et al. 2003, Markey et al. 2007). The photosystem II (PSII) herbicide diuron (3,(3,4-dichlorophenyl)-1,1dimethylurea) is commonly applied to control preemergent weeds in catchments flowing into the GBR, with approximately $197 \mathrm{t}$ applied annually in the sugar cane industry alone (Hamilton \& Haydon 1996). Peak application of diuron occurs during the wet season (November-January), when river flows are strong, increasing the potential delivery of diuron into the GBR Marine Park (GBRMP) (Haynes et al. 2000, Mitchell et al. 2005) and coinciding with the final stages of gametogenesis and larval development for reef corals on the GBR. Diuron concentrations measured from instantaneous samples within GBR catchments have been recorded as high as $8.5 \mu \mathrm{g} \mathrm{l}^{-1}$ in the 
mouth of the Pioneer River (Simpson 2002, Mitchell et al. 2005), $10 \mu \mathrm{g} \mathrm{kg}^{-1}$ in subtidal sediments and $1.7 \mu \mathrm{g}$ $\mathrm{kg}^{-1}$ in intertidal seagrasses of the GBR lagoon (Haynes et al. 2000). Low but persistent concentrations of diuron within some inshore habitats of the GBRMP are likely, although more extensive sampling is required to determine the duration of elevated levels (Haynes et al. 2000, Mitchell et al. 2005). The moderately high solubility of diuron $\left(42 \mathrm{mg} \mathrm{l}^{-1}\right)$ combined with high application rates have led to concern that diuron may be one of the most harmful agrochemical pollutants to GBR organisms and ecosystems (Haynes et al. 2000).

Diuron inhibits the PSII electron transport chain of symbiotic Symbiodinium spp. (zooxanthellae) in adult corals within hours, at concentrations as low as $0.3 \mu \mathrm{g}$ $\mathrm{l}^{-1}$ (Jones \& Kerswell 2003, Jones et al. 2003). The incorporation of carbon from photosynthesis within isolated Symbiodinium spp. has also been shown to decrease by $30 \%$ at $2 \mu \mathrm{g} \mathrm{l}^{-1}$ and by 60 to $70 \%$ at $10 \mu \mathrm{g}$ $\mathrm{l}^{-1}$ (Owen et al. 2003). Photosynthetic performance of symbiotic juvenile corals is affected at similar concentrations and typically results in bleaching (loss of Symbiodinium spp. and/or photosynthetic pigments) after medium term $(4 \mathrm{~d})$ diuron exposures (Negri et al. 2005). Diuron has no known direct impact on the cellular function of the invertebrate host. Juveniles of Acropora tenuis without symbionts (i.e. aposymbiotic) exposed to concentrations of diuron as high as $100 \mathrm{\mu g}$ $\mathrm{l}^{-1}$ for $10 \mathrm{~d}$ exhibited no morphological abnormalities such as tissue detachment or death (Watanabe et al. 2006). The fertilisation of gametes and the metamorphosis of aposymbiotic larvae of A. millepora were similarly unaffected by high diuron concentrations (Negri et al. 2005). While there is clear evidence that low to medium concentrations $\left(0.2\right.$ to $\left.10 \mu \mathrm{g} \mathrm{l}^{-1}\right)$ of diuron have acute, deleterious impacts on photosynthesis and carbohydrate production in Symbiodinium spp. (Jones \& Kerswell 2003, Jones et al. 2003, Owen et al. 2003, Negri et al. 2005), nothing is known about potential chronic impacts arising from long-term sublethal exposures.

In plants and algae, diuron causes photoinhibition within chloroplasts by competing with plastoquinone for the $\mathrm{Q}_{\mathrm{B}}$ binding site on the $\mathrm{D} 1$ protein within the PSII. Thus, diuron blocks light-induced electron transport from water to the $Q_{B}$ site, reducing the efficiency of photosynthetic processes and interfering with repair mechanisms involved in the synthesis of new D1 protein (Oettmeier 1992, Jones et al. 2003). Short-term studies on the toxicity of diuron to reef corals have shown that it is a fast-acting inhibitor of photosynthesis and demonstrate that exposure to $1 \mu \mathrm{g} \mathrm{l}^{-1}$ causes secondary damage to PSII reaction centres in illuminated samples (Jones \& Kerswell 2003, Jones et al. 2003,
Negri et al. 2005). Ultimately, diuron-induced photoinhibition disrupts light-dependent reactions of photosynthesis by reducing the linear electron transport through PSII that leads to the formation of ATP and NADPH (Oettmeier 1992, Jones et al. 2003). These 2 end products are essential substrates for the reduction of carbon dioxide to form carbohydrates and glycerol within the light-independent reactions of photosynthesis (Oettmeier 1992, Finazzi \& Forti 2004, Jones 2005). Since diuron reduces the fixation of carbon within symbionts (Owen et al. 2003), the translocation of photosynthetic products (carbohydrates and glycerol) into the coral host from symbiont photosynthesis will also be reduced following chronic diuron exposure.

The energy budget of an organism is finely balanced, so reductions in energy acquisition typically impact the amount of energy available for growth and reproduction (Stearns 1992). Reports of decreased reproductive output and larval development for corals with reduced densities of Symbiodinium spp., either due to temperature-induced bleaching (MichalekWagner \& Willis 2001) or nutrient enrichment (Loya et al. 2004), are consistent with reduced energy acquisition having flow-on effects for gametogenesis in corals. Both gametogenesis (production of oocytes and sperm) and larval development require protracted energy investment to produce eggs and larvae that are high in carbon-rich lipids (Arai et al. 1993). Heterotrophy and autotrophy are both critical to the energy budget of the coral holobiont, although evidence that the production of lipid is predominantly stimulated by the presence of light for photosynthesis (Crossland et al. 1980, Anthony \& Fabricius 2000) highlights the potential importance of photosynthetically derived energy for gamete and larval development in corals. Moreover, it has been shown that heterotrophy may free up photosynthetically derived resources for reproduction. For example, the immediate metabolic requirements of symbiotic corals that were fed brine shrimp were met from heterotrophy, which meant that they stored more of the energy derived from photosynthesis as lipids (Szmant-Froelich 1981). The critical importance of photosynthetically derived carbohydrates for coral nutrition (Muscatine et al. 1984, Rinkevich 1989, Anthony \& Fabricius 2000), particularly throughout the 8 mo, energy-dependent period of gamete and larval production (Harrison \& Wallace 1990), suggests that gamete and larval development are likely to be sensitive indicators of reductions in photosynthetically derived carbon, such as those potentially caused by chronic diuron exposure.

Total lipid quantities within coral tissues provide an indication of reproductive status (Ward 1995b, Leuzinger et al. 2003), both for broadcast spawning species of Acropora and Montipora, whose eggs con- 
tain 60 to $72 \%$ lipid (Arai et al. 1993), and for brooding species such as Pocillopora damicornis, whose larvae contain $70 \%$ lipid by dry weight (Richmond 1987). It has been demonstrated that lipid content decreases following planulation of brooded larvae from tissues of P. damicornis (Ward 1995b). Furthermore, Leuzinger et al. (2003) concluded that lipids were the only component of coral tissue (cf. proteins and carbohydrates) to significantly decrease as a result of broadcast spawning. Thus, investment of energy into oogenesis, spermatogenesis and tissue repair following spawning may be estimated by a combination of fecundity measurements (egg number and size) and total lipid content of coral tissues before and after spawning (Leuzinger et al. 2003). The present study examines long-term effects of herbicide-induced photoinhibition on symbiotic broadcast spawning and brooding corals during the final stages of their gametogenic cycles. In particular, we investigate how reductions in energy (i.e. in photosynthetically derived carbohydrates available for translocation to the coral host) caused by chronic diuron exposures affect coral reproduction, including gametogenesis and reproductive output.

\section{MATERIALS AND METHODS}

Diuron exposure. Reproductively mature colonies of Acropora tenuis and A. valida (20 to $30 \mathrm{~cm}$ in diameter) were collected from Nelly Bay, Magnetic Island, Australia $\left(19^{\circ} 10^{\prime} \mathrm{S}, 146^{\circ} 52^{\prime} \mathrm{E}\right)$ from August 10 to 25, 2003 (A. tenuis), and on August 3, 2004 (A. valida), approximately 10 and $13 \mathrm{wk}$, respectively, before the predicted nights of spawning. Reproductively mature colonies of Pocillopora damicornis $(15$ to $25 \mathrm{~cm}$ in diameter) were collected from Horseshoe Bay, Magnetic Island $\left(19^{\circ} 06^{\prime} \mathrm{S}, 146^{\circ} 51^{\prime} \mathrm{E}\right)$ on February 20, 2004, 4 wk before predicted planulation. Twenty-four colonies of each species were transported to outdoor aquaria at the Australian Institute of Marine Science (AIMS), Townsville, for experimental diuron exposures. An additional 8 colonies of each species were reattached at their sites of collection (3 to $4 \mathrm{~m}$ depth) as reef controls and later collected and transported to AIMS 3 to $4 \mathrm{~d}$ prior to spawning.

Corals were exposed to 3 experimental treatments: $0 \mu \mathrm{g} \mathrm{l}^{-1}$ diuron (tank controls), a $1.0 \mu \mathrm{g} \mathrm{l}^{-1}$ low-dose diuron treatment (an ecologically relevant concentration that reduces effective quantum yields by $20 \%$ ) (Jones et al. 2003), and a $10 \mu \mathrm{g} \mathrm{l}^{-1}$ moderate-dose diuron treatment (selected because it reduces effective quantum yields by $80 \%$ ) (Jones et al. 2003). Corals were exposed to these treatments for 2 to 3 mo prior to either spawning (Acropora tenuis for $53 \mathrm{~d}$, A. valida for $90 \mathrm{~d}$ ) or planulation (Pocillopora damicornis for $67 \mathrm{~d}$ ).
Exposure times were selected to ensure that photosynthesis was affected for the final 2 to 3 mo of the typical 8 to 9 mo gametogenic cycle (Harrison \& Wallace 1990). Each treatment was performed outdoors in 5001 tanks with unfiltered oceanic seawater that was settled in a header tank before flowing into experimental tanks at a flow rate of $31 \mathrm{~min}^{-1}$. Seawater temperatures in the tanks ranged from $26^{\circ} \mathrm{C}$ in the spring and fall to $29^{\circ} \mathrm{C}$ in summer months, closely paralleling local patterns in seasonal seawater temperatures. Natural food sources (plankton, suspended particulate matter, detritus and sediment) were present in the seawater and available to experimental corals throughout their exposures to diuron, providing ample nitrogen and phosphorous sources for protein synthesis. Tanks were shaded to $20 \%$ of full sunlight intensity (maximum irradiance of $350 \mu \mathrm{mol}$ quanta $\mathrm{m}^{-1} \mathrm{~s}^{-1}$ ), which is similar to light conditions at a depth of $3 \mathrm{~m}$. Corals were monitored for partial colony mortality, as indicated by tissue loss exposing bare skeleton on some branches or parts thereof, or full colony mortality (full loss of tissue on every branch of the colony).

For each of the 3 treatments 2 tanks were used, and 4 large reproductive colonies of each species were maintained within each tank during the 3 separate exposure experiments. A multichannel peristaltic pump was used to deliver a stock solution of laboratory grade diuron (98\%) (Sigma Pharmaceuticals). Nominal diuron concentrations were verified in 2 representative tanks per treatment by analysing 4 water samples collected at $3 \mathrm{wk}$ intervals during the first Acropora tenuis experiment. Diuron concentrations were measured as described in Negri et al. (2005). Mean ( \pm SE) diuron concentrations within the replicate tanks of each treatment were $0.91 \pm 0.05$ and $8.8 \pm 0.2 \mu \mathrm{g}^{-1}$, respectively. Seawater from the diuron tanks was diluted 100-fold in the aquarium/stormwater outflow and pumped into a 1.5 ha artificial wetland/evaporation pond for disposal. During the predicted weeks of spawning (i.e. the $7 \mathrm{~d}$ following the October full moons in 2003 and 2004), A. tenuis and A. valida colonies were monitored for spawning activity between dusk and 23:00 h. For $2 \mathrm{wk}$ during the March and April new moons, outflows from the Pocillopora damicornis tanks were run through a $100 \mu \mathrm{m}$ mesh plankton trap to collect released planulae and track reproductive output.

Effects of parental diuron exposure. Photosynthetic yields: The photosynthetic efficiency (maximum quantum yield and effective quantum yield) of Symbiodinium spp. within host tissues of the 3 coral species was estimated from chlorophyll fluorescence measurements taken with a pulse amplitude modulated (PAM) chlorophyll fluorometer (Maxwell \& Johnson 2000) (DIVING-PAM, Walz, with Out Gain set to 4 and Measuring Intensity set to 8). Measurements were taken 
from each colony on a plane perpendicular to branches by placing a $2 \mathrm{~mm}$ fibre-optic probe gently against the surface of the coral tissue. Minimum fluorescence ( $F$ in illuminated samples or $F_{0}$ in dark-adapted samples) was determined by applying a weak pulse-modulated red measuring light $\left(0.15 \mu \mathrm{mol}\right.$ quanta $\left.\mathrm{m}^{-2} \mathrm{~s}^{-1}\right)$. The maximum fluorescence $\left(F_{\mathrm{m}}{ }^{\prime}\right.$ in illuminated samples or $F_{\mathrm{m}}$ in dark-adapted samples) was then measured, following application of a saturating pulse of actinic light $\left(>3000 \mu \mathrm{mol}\right.$ quanta $\mathrm{m}^{-2} \mathrm{~s}^{-1}$ ). Both the effective quantum yield from light-adapted symbionts, $\left(F_{\mathrm{m}}{ }^{\prime}-\right.$ $F) / F_{\mathrm{m}}{ }^{\prime}=\Delta F / F_{\mathrm{m}}{ }^{\prime}$, and the maximum quantum yield of dark-adapted symbionts, $\left(F_{\mathrm{m}}-F_{0}\right) / F_{\mathrm{m}}=F_{\mathrm{v}} / F_{\mathrm{m}}$, were measured. Twice a week, 6 replicate measurements were taken from random sectors of each colony, but standardized so that they were always taken about halfway down branches that were at least $5 \mathrm{~cm}$ from colony margins to avoid areas of new growth. Measurements were taken at 15:00 to $15: 30 \mathrm{~h}$ to obtain $\Delta F / F_{\mathrm{m}}{ }^{\prime}$ and at 1 to $1.5 \mathrm{~h}$ after sunset to obtain $F_{\mathrm{v}} / F_{\mathrm{m}}$. Measurements were not taken on branches that had suffered partial or full mortality. A more detailed description of the use of PAM fluorometry to monitor photoinhibition in Symbiodinium spp. can be found in Jones et al. (2003).

Density of Symbiodinium spp.: Immediately following the conclusion of the experimental diuron exposures, 3 branches were collected from each colony. All branch samples were collected $\sim 5 \mathrm{~cm}$ from colony margins. Coral tissues were stripped with a jet of $0.2 \mu \mathrm{m}-$ filtered seawater $(\sim 12 \mathrm{ml})$ and an airbrush (Szmant \& Gassman 1990). Tissue slurries were homogenized for $15 \mathrm{~s}$ and the volume of the homogenate recorded. Densities of Symbiodinium spp. were determined with a haemocytometer. Total protein within the slurries was determined using BIO-RAD DC Protein Assay kits (Bio-Rad Laboratories) as per the manufacturer's instructions. Densities of Symbiodinium cells were normalized to total protein (number of cells per mg protein) because total protein has been shown to remain constant before and after spawning in a range of coral species (Leuzinger et al. 2003) and has also been used to normalize coral tissue biomass in previous studies (Edmunds \& Gates 2002).

Photosynthetic pigment composition: Photosynthetic pigments (chlorophylls and carotenoids) were extracted from 3 additional branches collected from each colony of Acropora valida immediately following the conclusion of the experimental exposures. All branch samples were collected $\sim 5 \mathrm{~cm}$ from colony margins. Each branch was placed in a $15 \mathrm{ml}$ centrifuge tube with $4 \mathrm{ml}$ of pre-chilled isopropanol:methanol $(50: 50 \mathrm{v} / \mathrm{v})$. Each tube was vortexed for $30 \mathrm{~s}$ and stored in the dark on ice for $30 \mathrm{~min}$ to protect carotenoids from degradation. The supernatant was then removed and the process repeated (a third extract revealed that the combined efficiency of the first 2 extracts was $>95 \%$ ). The combined supernatants were then centrifuged at $2300 \times g$ for 2 min prior to analysis. High performance liquid chromatography (HPLC) analysis was performed on a Waters 600 HPLC, combined with a Waters PDA 996 photodiodearray detector. Photosynthetic pigments were separated using a $5 \mu \mathrm{m}, 250 \times 4.6$ mm Alltima octadecylsilane (ODS) column (Alltech)

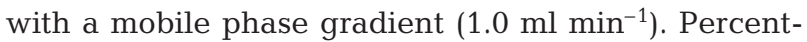
ages of the Solvents $\mathrm{A}, \mathrm{B}$ and $\mathrm{C}$, respectively, were as follows: $0 \mathrm{~min}$ : $100,0,0 \%$; 0 to 4 min linear gradient to $0,100,0 \%$; 4 to 15 min gradient to $0,80,20 \%$; 15 to 25 min gradient to $0,20,80 \% ; 25$ to 35 min hold at 0,20 , $80 \%$. Solvent A was methanol:0.5 M ammonium acetate (aq.; pH 7.2, 80:20 v/v). Solvent B was acetonitrile:water $(90: 10 \mathrm{v} / \mathrm{v})$. Solvent C was 100\% ethyl acetate (HPLC grade). Peridinin, diadinoxanthin, diatoxanthin and chlorophylls $a$ and $c_{2}$ (chl $a$ and chl $c_{2}$ ) standards were obtained from the International Agency for ${ }^{14} \mathrm{C}$ Determination (Denmark) and $\beta$ carotene standard was obtained from Sigma-Aldrich. The identified peaks $(91 \%$ of area on the chromatogram at $440 \mathrm{~nm}$ ) were confirmed by comparison of retention times, absorption spectra and spiking with the above standards. The dinoxanthin peak (see Fig. $5 \mathrm{~A}, 24 \mathrm{~min}$, an additional $3 \%$ of the area on the chromatogram) was identified based upon its absorption spectra and by calculating retention time ratios from the diadinoxanthin standard and published data (Wright \& Jeffrey 1997). Coral tissue was lost during the pigment extraction procedure, so pigment concentrations were normalized to skeletal surface area $\left(\mathrm{cm}^{-2}\right)$ using the wax weight method (Stimson 1987).

Reproductive investment. Total lipid content: Two branches were sampled from each colony at 3 stages throughout the study: (1) before diuron exposure, (2) just prior to either spawning (i.e. 8 and $12 \mathrm{wk}$ after starting experimental exposures for Acropora tenuis and A. valida, respectively) or planulation (i.e. 4 and $8 \mathrm{wk}$ after the start of exposure for Pocillopora damicornis), and (3) following either spawning (i.e. within 3 d of spawning) or final planulation (i.e. $1 \mathrm{~d}$ after no larvae were captured in outflow nets following the second planulation event). All branch samples were collected $\sim 5 \mathrm{~cm}$ from colony margins. Samples were frozen in liquid nitrogen and stored at $-80^{\circ} \mathrm{C}$ prior to processing. Branches were ground into a homogeneous powder of coral tissue and skeleton with a frozen mortar and pestle, and the tissue was freezedried prior to total lipid extraction. Total lipids were extracted from $0.5 \mathrm{~g}$ of tissue powder with dichloromethane:methanol $(2: 1 \mathrm{v} / \mathrm{v})$ following the method described by Harland et al. (1992). Since coral branches were ground into a fine homogeneous pow- 
der, total lipid content was standardized against total protein (Edmunds \& Gates 2002).

Fecundity of broadcast spawning corals: Branches from the broadcast spawning corals Acropora tenuis and $A$. valida were sampled ( $\sim 5 \mathrm{~cm}$ from colony margins) at the same time as branches used for lipid analysis and fixed in a solution of $10 \%$ formaldehyde in seawater for $24 \mathrm{~h}$. Branches were then decalcified in a solution of $6 \%$ formic acid and $2 \%$ formaldehyde in distilled water. Four polyps, located at least $2 \mathrm{~cm}$ from the tip of branches to avoid sterile zones, were dissected from each colony under a dissecting microscope and the number of eggs per polyp counted. Individual eggs were separated from mesenteries and photographed. Mature eggs of Acropora spp. are irregular in shape so the circumference of each egg was traced using Optimas (Media Cybernetics) and the planar surface area calculated as a proxy for egg size.

Fecundity of brooding coral: One branch per colony ( $\mathrm{n}=6$ colonies for each treatment) was randomly sampled from the internal brooder Pocillopora damicornis, as described above for lipid analysis and fixed and decalcified as described above for broadcast spawning corals. Each branch was dissected longitudinally to expose the aboral sections of polyps where developing larvae were visible. The number of polyps containing planulae was expressed as a percentage of the total number of polyps examined per branch ( $\mathrm{n}=560 \pm 61$ polyps per branch dissection). The total number of reproductive polyps included (1) young early stage eggs with a central nucleus, (2) mature late stage eggs with nuclei located peripherally, (3) planula larvae without mesenteries and (4) planula larvae with mesenteries. Stages 3 and 4 indicate that successful fertilisation has occurred. Only 1 branch of the 36 dissected contained unfertilized eggs. Individual planulae were separated from the polyp and the size and surface areas calculated as for eggs of broadcast spawners.

Data analysis. Changes in mean photosynthetic yields (i.e. both effective and maximum quantum yields as measured by PAM fluorometry) were compared among treatments using repeated-measures ANOVA $(\alpha=0.05)$, with sampling occasion as the repeated measure over time (Zar 1996). For both measures of photosynthetic efficiency, only yield values obtained during the diuron exposure were used in the analysis (i.e. pre-exposure and recovery values were not included). Mean photosynthetic pigment concentrations and lipid composition ratios were compared across the 4 diuron treatments with a 1-way ANOVA $(\alpha=0.05)$. Data not conforming to the assumptions of normality were log transformed prior to analyses. Symbiodinium spp. density, total lipid content and all fecundity measurements were compared for each species using 1 -way ANOVAs $(\alpha=0.05)$. Tukey's honestly significant difference (HSD) test was used to identify significantly different means. All statistical analyses were performed on SPSS 11.0.

\section{RESULTS}

\section{PAM chlorophyll fluorescence measurements}

Mean effective quantum yields $\left(\Delta F / F_{\mathrm{m}}{ }^{\prime}\right)$ of the lightadapted symbionts within control colonies of Acropora tenuis, A. valida and Pocillopora damicornis $\left(0 \mu \mathrm{g} \mathrm{l}^{-1}\right.$ diuron tanks) were $0.67 \pm 0.01,0.61 \pm 0.01$ and $0.69 \pm$ $0.01( \pm \mathrm{SE})$, respectively, throughout the entire exposure period (Fig. 1A). In comparison, long-term exposures to nominal concentrations of 1.0 and $10 \mu \mathrm{g} \mathrm{l}^{-1}$ diuron caused significant reductions in the mean $\Delta F / F_{\mathrm{m}}{ }^{\prime}$ of the light-adapted symbionts for all 3 species and at both concentrations tested $\left(A\right.$. tenuis: $F_{(2,14)}=$ 560, $\mathrm{p}<0.01$; A. valida: $F_{(2,21)}=696, \mathrm{p}<0.01$; and $P$. damicornis: $F_{(2,15)}=842, \mathrm{p}<0.01$ ) (Fig. 1A). PSII photoinhibition occurred rapidly (within the first $24 \mathrm{~h}$ ) and
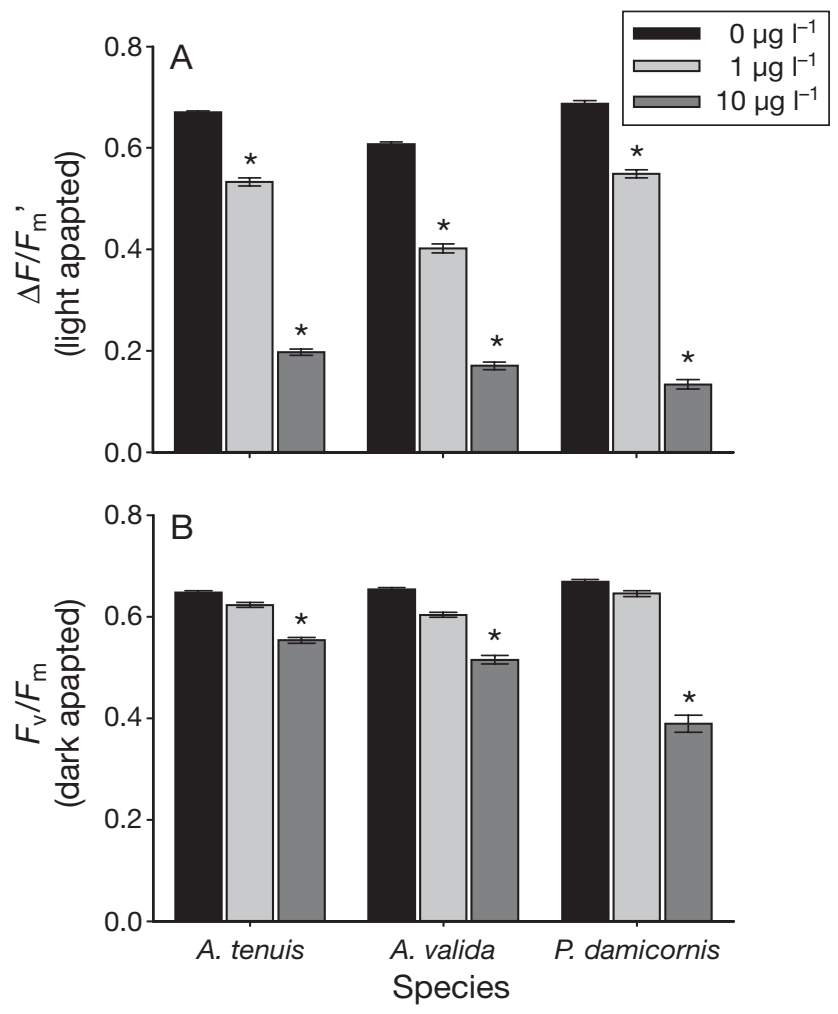

Fig. 1. Symbiodinium spp. in hospite in Acropora tenuis, A. valida, and Pocillopora damicornis. Photosynthetic efficiencies of Symbiodinium spp. among corals exposed to constant flow-through concentrations of diuron $(0,1.0$ and $10 \mu \mathrm{g}$ $\mathrm{l}^{-1}$ ) for 2 to 3 mo prior to reproductive events: (A) mean $\Delta F / F_{\mathrm{m}}{ }^{\prime}$ effective quantum yield (light adapted); and (B) mean $F_{\mathrm{v}} / F_{\mathrm{m}}$ maximum quantum yield (dark adapted). Data are means \pm $\mathrm{SE}, \mathrm{n}=6$ colonies. ${ }^{*}$ Means significantly different from the $0 \mu \mathrm{g}^{-1}$ control $(\mathrm{p}<0.05)$ 
$\Delta F / F_{\mathrm{m}}{ }^{\prime}$ remained depressed during the entire exposure period for each species (Fig. 2, only $A$. tenuis data shown). Mean $\Delta F / F_{\mathrm{m}}{ }^{\prime}$ values for all 3 species were reduced to approximately 80 and $25 \%$ that of the controls for the 1.0 and $10 \mu \mathrm{g} \mathrm{l}^{-1}$ diuron treatments respectively (Fig. 1A). The $\Delta F / F_{\mathrm{m}}{ }^{\prime}$ values for each species returned to control levels after 3 to $5 \mathrm{~d}$ recovery in uncontaminated seawater (Fig. 2A, A. tenuis).

The mean maximum quantum yields $\left(F_{\mathrm{v}} / F_{\mathrm{m}}\right)$ from dark-adapted colonies of Acropora tenuis, A. valida and Pocillopora damicornis were identical (0.65 \pm 0.01$)$ in the control tanks containing uncontaminated seawater ( $0 \mu \mathrm{g} \mathrm{l}^{-1}$ diuron) (Fig. 1B). $F_{\mathrm{v}} / F_{\mathrm{m}}$ of the 3 species were reduced significantly during the $10 \mu \mathrm{g} \mathrm{l}^{-1}$ exposures: A. tenuis to $85 \%\left(F_{(2,15)}=55.8, \mathrm{p}<0.01\right), A$. valida to $80 \%\left(F_{(2,21)}=53.4, \mathrm{p}<0.01\right)$ and $P$. damicornis to $58 \%$ of the mean value for control corals $\left(F_{(2,15)}=74.4\right.$, $\mathrm{p}<0.01$ ) (Fig. 1B). Reductions in maximum quantum yields were recorded for each species throughout the experimental exposures, indicating chronic photoinhibition (Jones \& Kerswell 2003). $F_{\mathrm{v}} / F_{\mathrm{m}}$ for A. valida exposed to $10 \mu \mathrm{g} \mathrm{l}^{-1}$ diuron declined gradually over time, dropping to as low as $80 \%$ of the control value on
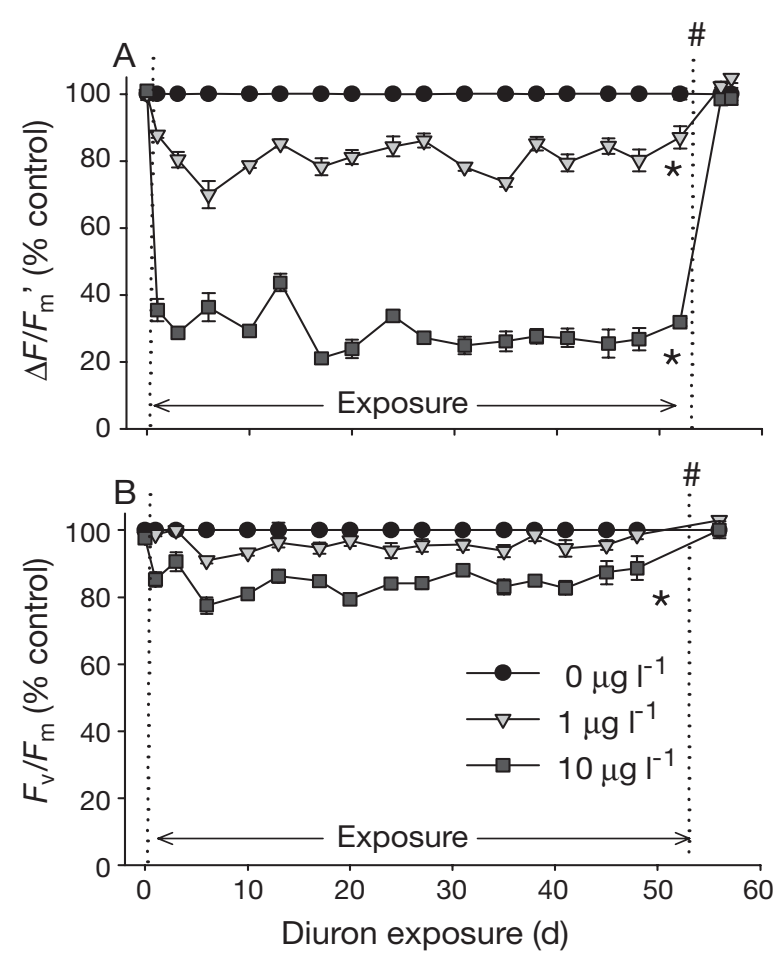

Fig. 2. Symbiodinium spp. in hospite in Acropora tenuis. Photosynthetic efficiencies (as a percent of control values) of Symbiodinium spp. associated with A. tenuis during a $53 \mathrm{~d}$ exposure to diuron and a $3 \mathrm{~d}$ recovery in uncontaminated seawater: (A) mean $\Delta F / F_{\mathrm{m}}{ }^{\prime}$ effective quantum yield (light adapted); and (B) mean $F_{\mathrm{v}} / F_{\mathrm{m}}$ maximum quantum yield (dark adapted). Data are means $\pm \mathrm{SE}, \mathrm{n}=6$ colonies. *Means significantly different from the $0 \mu \mathrm{g} \mathrm{l}^{-1}$ control $(\mathrm{p}<0.05)$; \# = spawning event
Day 41 of exposure. In contrast, $F_{\mathrm{v}} / F_{\mathrm{m}}$ for $A$. tenuis colonies in the $10 \mathrm{\mu g} \mathrm{l}^{-1}$ diuron treatment dropped to $85 \%$ of the control values on Day 6 of exposure and then remained consistent throughout the remaining $7.5 \mathrm{wk}$ of treatment. Symbionts in all surviving adult coral colonies recovered rapidly when returned to uncontaminated seawater, exhibiting $F_{\mathrm{v}} / F_{\mathrm{m}}$ values similar to control colonies at the end of the diuron exposure (Fig. 2B).

\section{Bleaching and mortality of experimental corals}

All colonies of Acropora tenuis and Pocillopora damicornis survived the 1.0 and $10 \mu \mathrm{g} \mathrm{l}^{-1}$ diuron treatments. All colonies of $A$. valida survived except for 2 of the 8 colonies in the $10 \mu \mathrm{g} \mathrm{l} \mathrm{l}^{-1}$ treatment, which died following 6 to $7 \mathrm{wk}$ of diuron exposure. The remaining colonies of $A$. valida in the $10 \mu \mathrm{g} \mathrm{l}^{-1}$ treatment tanks sustained partial mortality. No partial mortality was observed for the other 2 species in any of the treatments.

Bleaching was not observed for Acropora tenuis following long-term photoinhibition caused by 1.0 and $10 \mu \mathrm{g} \mathrm{l}^{-1}$ diuron exposures. These macroscopic observations were corroborated by the consistent Symbiodinium spp. densities found in comparisons among treatments (Fig. 3, $F_{(3,20)}=1.2, p=0.3$ ). All colonies of A. Valida in the $10 \mu \mathrm{g}^{-1}$ treatment exhibited patchy bleaching (visible to the naked eye) with some branches fully pigmented, some with patches of bleached tissue and others being completely devoid of pigmentation (Fig. 4). Severe bleaching preceded the partial and complete mortality described above. Nevertheless, densities of Symbiodinium spp. in the

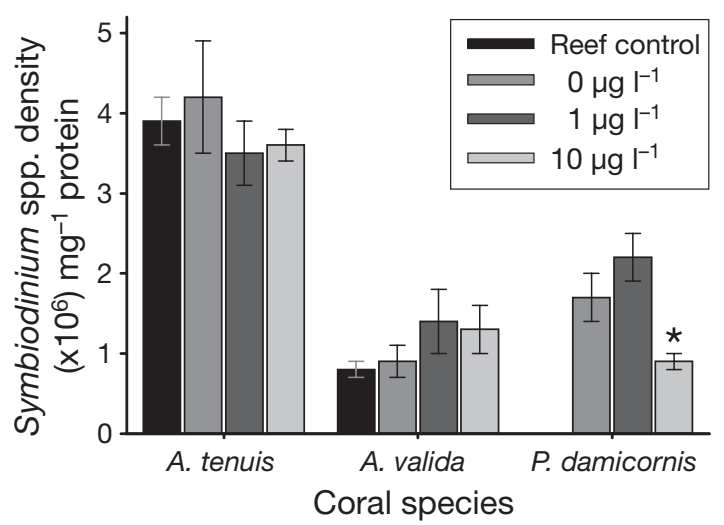

Fig. 3. Symbiodinium spp. in Acropora tenuis, A. valida and Pocillopora damicornis. Comparison of Symbiodinium spp. densities among reef coral colonies following 2 to 3 mo exposure to 4 diuron treatments (reef control, 0, 1.0 and $10 \mu \mathrm{g} \mathrm{l}^{-1}$ ). Data are means $\pm \mathrm{SE}, \mathrm{n}=6$ colonies per treatment. *Means significantly different from the $0 \mu \mathrm{g} \mathrm{l}^{-1}$ control $(\mathrm{p}<0.05)$ 

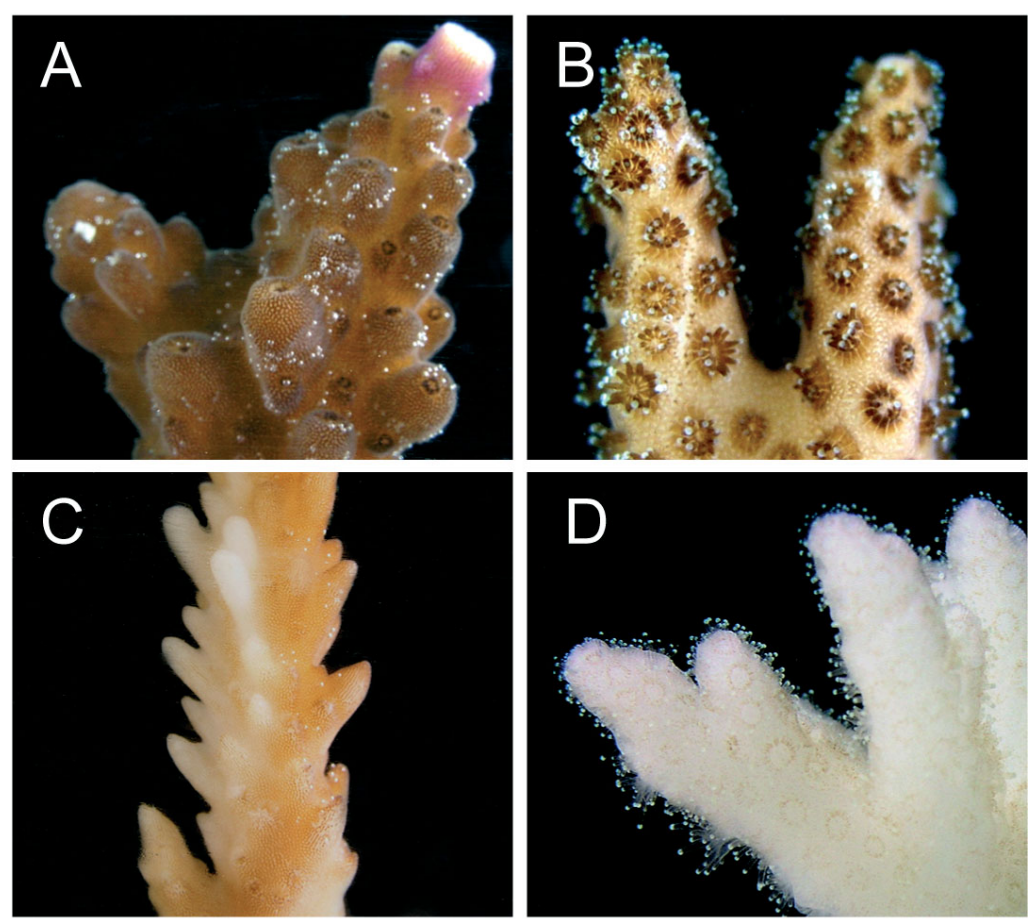

Fig. 4. Acropora valida and Pocillopora damicornis. Images of normally pigmented and bleached corals in control versus $10 \mu \mathrm{g} \mathrm{l}^{-1}$ diuron treatments: (A) A. valida in $0 \mu \mathrm{gl}^{-1}$; (B) P. damicornis in $0 \mu \mathrm{g} \mathrm{l}^{-1}$; (C) A. valida in $10 \mu \mathrm{gl}^{-1}$ diuron; (D) P. damicornis in $10 \mu \mathrm{g}^{-1}$ diuron

unbleached and patchily bleached branches of A. valida in the $10 \mathrm{\mu g} \mathrm{l}^{-1}$ treatment were not significantly lower than in branches of controls $\left(F_{(3,21)}=1.3, \mathrm{p}=0.3\right)$ (Fig. 3). Severe bleaching and loss of Symbiodinium spp. were observed for the $P$. damicornis colonies exposed to $10 \mathrm{\mu g}^{-1}$ diuron after $25 \mathrm{~d}$ of exposure, and the colonies remained bleached throughout the second planulation event in April $\left(F_{(2,15)}=6.0, \mathrm{p}=0.01\right)$ (Figs. 3 \& 4B, $0 \mu \mathrm{g}^{-1}$; Fig. 4D, $10 \mu \mathrm{g} \mathrm{l}^{-1}$ ).

\section{Photosynthetic pigment composition}

Major light harvesting pigments identified from Symbiodinium spp. within tissues collected from Acropora valida tank controls included chl a (44 mol\% of total pigments), chl $C_{2} \quad(12 \mathrm{~mol} \%)$ and peridinin (35 mol\%) (Fig. 5). Diadinoxanthin (7 mol\%) was the dominant pigment identified among those associated with oxidative stress and non-photochemical quenching (NPQ). We found minor peaks of the NPQ pigments, dinoxanthin (1.5 mol\%), diatoxanthin $(0.15 \mathrm{~mol} \%)$ and $\beta-\beta$ carotene $\left(1.5 \times 10^{-4} \mathrm{~mol} \%\right)$ (Fig. 5A). Total concentrations of the light-harvesting pigments chl $a, c_{2}$ and peridinin present in branches of A. valida within the $10 \mu \mathrm{g} \mathrm{l}^{-1}$ treatment were significantly reduced to $35 \%$ of concentrations found for the other 3 treatments $\left(F_{(3,8)}=8.0, \mathrm{p}=0.008\right)$ (Fig. 5B). Carotenoids involved with NPQ and oxidative stress (diadinoxanthin, dinoxanthin, diatoxanthin and $\beta-\beta$ carotene) were also significantly reduced to $36 \%$ of the other 3 treatments (Fig. 5B, $\left.F_{(3,8)}=7.8, \mathrm{p}=0.009\right)$ when exposed to $10 \mu \mathrm{g} \mathrm{l}^{-1}$ diuron. Although the total concentrations of these pigments were reduced following diuron exposure, the profiles (ratios) of the light-harvesting pigments: carotenoids were not affected (Fig. 5B). The mean ratio of peridinin: chl a remained unchanged at $0.82 \pm 0.04$ $\left(F_{(3,8)}=1.2, \mathrm{p}=0.4\right)$, as did the mean ratio of carotenoids (NPQ): chl $a$ at $0.22 \pm 0.01$ $\left(F_{(3,8)}=1.3, \mathrm{p}=0.3\right)$.

\section{Reproductive investment: total lipid content}

Total lipid content of the 2 broadcast spawning species Acropora tenuis and A. Valida did not change significantly within tissues of the reef and $0 \mu \mathrm{g} \mathrm{l}^{-1}$ control colonies during the 2 to 3 mo leading up to spawning (A. tenuis reef control: $F_{(2,17)}=2.6, \mathrm{p}=0.1$ (Fig. 6A); $A$. valida reef control: $F_{(2,17)}=0.44, \mathrm{p}=0.6 ;$ A. valida $0 \mu \mathrm{g} \mathrm{l}^{-1}$ control: $F_{(2,17)}=$ 1.9, $\mathrm{p}=0.2$ (Fig. 6B)). In contrast, exposure to $10 \mu \mathrm{g} \mathrm{l}^{-1}$ diuron resulted in significant reductions in total (parent + egg) lipid content within the tissues of both broadcast spawning species prior to spawning; total lipids dropped to approximately $40 \%$ of reef control values in $A$. tenuis $\left(F_{(3,20)}=4.8, \mathrm{p}=0.01\right)$ and to $15 \%$ of reef control values in $A$. valida $\left(F_{(3,20)}=5.1, \mathrm{p}=0.009\right)$. In A. valida, diuron concentrations as low as $1.0 \mu \mathrm{g} \mathrm{l}^{-1}$ also reduced lipid content to $\sim 25 \%$ of reef control colonies prior to spawning (Fig. 6B, $F_{(2,15)}=6.9, \mathrm{p}=$ $0.007)$. This decline in lipid content may be attributable to a drop in parental lipid storage since there was no further decline in lipid following spawning within the $1.0 \mu \mathrm{g} \mathrm{l}^{-1}$ treatment (Fig. 6B, p = 0.6). In the internal brooder Pocillopora damicornis, lipid content decreased significantly within the first $3.5 \mathrm{wk}$ of exposure to $10 \mu \mathrm{g} \mathrm{l}^{-1}$ of diuron leading up to the first planulation event. Lipid content remained significantly reduced in comparison to the other 2 treatments throughout the second month of exposure leading up to the second planulation event (Fig. 6C, $F_{(3,20)}=23.5, \mathrm{p}<0.001$ ).

Following spawning, lipid content declined further in colonies of Acropora tenuis (coral tissue only) in the $10 \mu \mathrm{g} \mathrm{l}^{-1}$ diuron treatment, consistent with the release of eggs (Fig. 6A). The 0 and $1.0 \mu \mathrm{g} \mathrm{l}^{-1}$ 

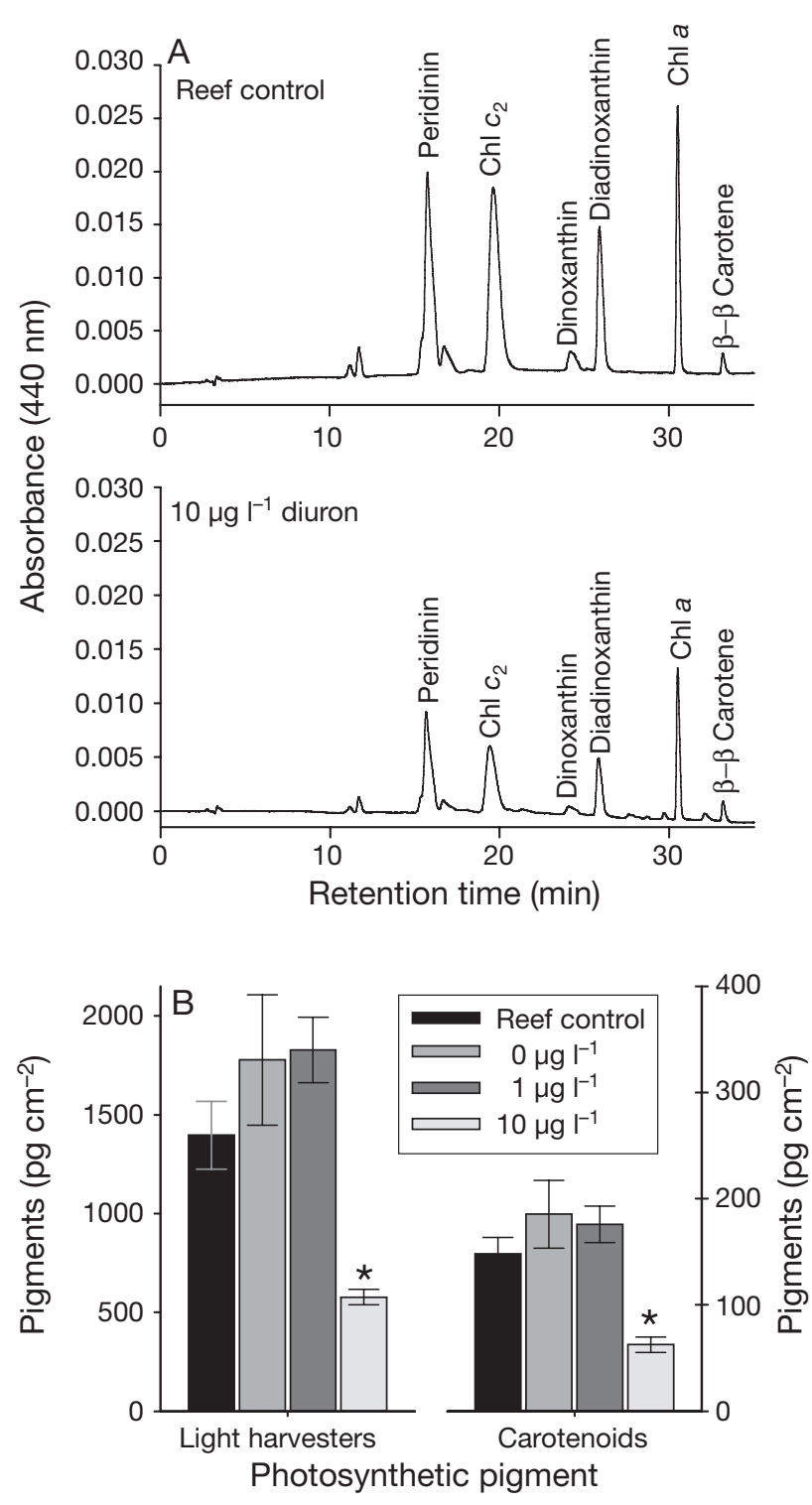

Fig. 5. Acropora valida. Photosynthetic pigments extracted from $A$. valida tissues following long-term diuron induced photoinhibition: (A) HPLC chromatogram of a pigment extract from A. valida whole tissue; (B) concentration of light harvesters (chlorophyll $a, c_{2}$ and peridinin) and xanthophyll carotenoids (diadinoxanthin, diatoxanthin and diandino-

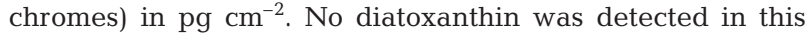
chromatogram. Data are means $\pm \mathrm{SE}, \mathrm{n}=3$ branches per treatment. *Means significantly different from the $0 \mu \mathrm{g} \mathrm{l}^{-1}$ control $(\mathrm{p}<0.05)$

colonies of $A$. tenuis spawned unexpectedly early, 2 or 3 nights before the full moon in October, but the precise timing of each spawning could not be recorded. Because the timing of spawning was unknown for this species, after-spawning total lipid values for these 2 treatments were omitted from the A. tenuis results (Fig. 6A).

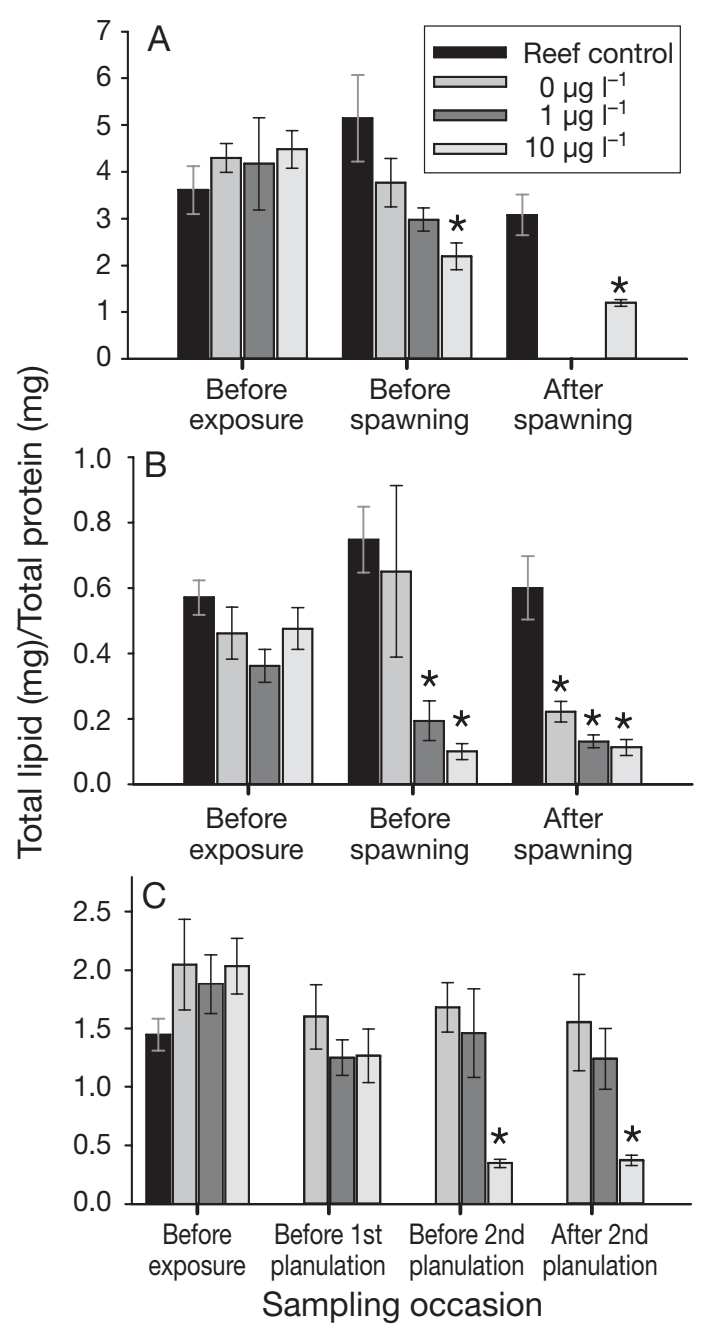

Fig. 6. Acropora tenuis, A. valida and Pocillopora damicornis. Comparison of total lipids (mg per mg protein) throughout long-term exposures to $0,1.0$ and $10 \mu \mathrm{g} \mathrm{l}^{-1}$ diuron within whole tissues of (A) A. tenuis, a broadcast spawner; (B) A. valida, a broadcast spawner; and (C) P. damicornis, an internal brooder. Data are means $\pm \mathrm{SE}, \mathrm{n}=6$ colonies per treatment. *Means significantly different from the $0 \mu \mathrm{g} \mathrm{l^{-1 }}$ control $(p<0.05)$

Pocillopora damicornis colonies exposed to $10 \mathrm{\mu g}^{-1}$ also exhibited a significant drop in lipid content, from $1.3 \pm 0.2$ to $0.35 \pm 0.04 \mathrm{mg}$ lipid $\mathrm{mg}$ protein $^{-1}$ within $20 \mathrm{~d}$, as measured from the sample taken before the first planulation event to the sample taken before the second planulation (Fig. 6C, Tukey HSD $p=0.005$ ). Total lipid remained at this low level until after the second planulation event. Reductions in lipid content were only observed in colonies of $P$. damicornis exposed to $10 \mathrm{\mu g} \mathrm{l}^{-1}$ diuron, with total lipid content remaining consistent during the 3 mo experiment for the tank controls $\left(0 \mu \mathrm{g} \mathrm{l}^{-1}\right)$ and the $1.0 \mu \mathrm{g} \mathrm{l}^{-1}$ treatment colonies (Fig. 6C). 


\section{Reproductive investment: fecundity of broadcast spawning corals}

Reproductive activity following exposure to diuron also differed dramatically between the 2 broadcast spawning species. Colonies of Acropora tenuis exposed to $10 \mu \mathrm{g} \mathrm{l} \mathrm{l}^{-1}$ successfully spawned gametes and there was no significant reduction in either the average number of eggs per polyp $\left(F_{(3,20)}=1.2, \mathrm{p}=0.3\right)$ or the average egg size produced $\left(F_{(3,20)}=0.68, \mathrm{p}=0.6\right)$ (Table 1). In contrast, very few polyps of $A$. valida exposed to similar levels of photoinhibition in the $10 \mu \mathrm{g}$ $\mathrm{l}^{-1}$ diuron treatment contained eggs, resulting in significantly reduced polyp fecundity $\left(F_{(3,12)}=7.6, \mathrm{p}=0.004\right)$ (Table 1). Although eggs of $A$. valida that were present in the $10 \mu \mathrm{g} \mathrm{l}^{-1}$ treatment did not differ in size in comparison to eggs in the other 3 treatments (Table 1 , $F_{(3,17)}=0.8, \mathrm{p}=0.5$ ), no spawning (reproductive output) was observed. Less severe photoinhibition by $1.0 \mathrm{\mu g} \mathrm{l}^{-1}$ diuron did not affect fecundity or egg size of either species, suggesting that the reduction in total lipid content observed for branches of A. valida in this treatment (Fig. 6B) occurred within the somatic tissue rather than the reproductive tissue of this species (Table 1).

\section{Reproductive investment: fecundity of internal brooder}

Approximately 150 to 200 planula larvae of Pocillopora damicornis were collected daily from most exposure tanks during 2 separate planulation events, which each lasted approximately 7 to $10 \mathrm{~d}$ following the new moons in March and April. All of the colonies $(n=8)$ within the $10 \mathrm{\mu g} \mathrm{l}^{-1}$ treatment group were bleached and failed to release larvae during the second planulation event in April following $53 \mathrm{~d}$ of severe photoinhibition. Dissections of branches indicated that the size of fully developed planulae did not vary significantly among diuron treatments $\left(F_{(2,3)}=0.9, \mathrm{p}=0.5\right)$ (Table 1$)$. Moreover, no unfertilized oocytes were detected, indicating that diuron did not negatively affect the process of internal fertilisation. In contrast, the average number of reproductive polyps per branch varied widely. Colonies in the $1.0 \mu \mathrm{g}$ $\mathrm{l}^{-1}$ treatment contained a significantly greater number of reproductive polyps than colonies from the other 2 treatments sampled before the second planulation $\left(F_{(2,15)}=3.8, \mathrm{p}=0.04\right)$ (Table 1). Although the severely bleached colonies in the $10 \mu \mathrm{g} \mathrm{l}^{-1}$ treatment did not release larvae during the second planulation event in April, $33 \%$ of the sampled branches still contained reproductive polyps, indicating that the host colony may have been storing the developed larvae as a possible energy source.

\section{DISCUSSION}

Our results demonstrate that photoinhibition caused by exposure to moderate levels of diuron $\left(10 \mathrm{\mu g} \mathrm{l}^{-1}\right)$ in the final months of gametogenesis or larval development reduces the reproductive output of corals, and in some cases, inhibits reproduction completely. We found that the broadcast spawning coral Acropora valida and the brooding coral Pocillopora damicornis were particularly sensitive to energy deficiencies caused by diuroninduced photoinhibition. These spe-

$\begin{array}{lcc}\begin{array}{c}\text { Pocillopora damicornis } \\ \text { March (first planulation) }\end{array} & & \\ 0 \mu \mathrm{l} \mathrm{l}^{-1} & 2.1 \pm 0.9 & (\mathrm{n}=131 \text { planulae total) } \\ 1 \mu \mathrm{g} \mathrm{l}^{-1} & 1.1 \pm 0.7 & 155 \pm 7 \\ 10 \mu \mathrm{g} \mathrm{l}^{-1} & 0.9 \pm 0.4 & 218 \pm 11 \\ \mathrm{April} \mathrm{(second} \mathrm{planulation)} & & 177 \pm 11 \\ 0 \mu \mathrm{g} \mathrm{l}^{-1} & 0.2 \pm 0.2 & (\mathrm{n}=124 \text { planulae total) } \\ 1 \mu \mathrm{g} \mathrm{l}^{-1} & 4.1 \pm 1.7^{*} & 203 \pm 7 \\ 10 \mu \mathrm{g} \mathrm{l}^{-1} & 1.7 \pm 1.1 & 285 \pm 14 \\ & & 313 \pm 15\end{array}$


cies ultimately failed to release gametes or larvae following experimental exposures to $10 \mu \mathrm{g} \mathrm{l}^{-1}$ diuron throughout the final $13 \mathrm{wk}$ of gametogenesis or $9.5 \mathrm{wk}$ of larval development, respectively. In contrast, identical concentrations of diuron, although for 2 to $4 \mathrm{wk}$ shorter experimental periods, had negligible impact on A. tenuis, which spawned successfully following exposure throughout the final 7.5 wk of gametogenesis. For the more sensitive $A$. valida, exposure to $10 \mu \mathrm{g} \mathrm{l}^{-1}$ diuron resulted in partial mortality (loss of tissue on some branches) in $100 \%$ and full mortality in $25 \%$ of experimental corals ( $\mathrm{n}=8$ colonies). This is the only documented case of coral mortality resulting from photoinhibition at moderate $\left(10 \mu \mathrm{g} \mathrm{l}^{-1}\right)$ diuron concentrations.

The inhibition of reproduction in colonies of Acropora valida and Pocillopora damicornis and reduced lipid (energy storage) in A. tenuis exposed to $10 \mu \mathrm{g} \mathrm{l}^{-1}$ diuron were likely caused by significant reductions in photosynthetic energy available for allocation to reproductive processes. Diuron induces rapid inhibition of electron transport through the PSII (Jones et al. 2003) and significantly reduces carbon fixation in Symbiodinium spp. (Owen et al. 2003). Consistent reductions in effective quantum yields (mean $\Delta F / F_{\mathrm{m}}{ }^{\prime}$ ) to between $19 \%$ (P. damicornis) and $28 \%$ (A. tenuis and A. valida) of controls in the $10 \mathrm{\mu g} \mathrm{l}^{-1}$ diuron treatments imply dramatic reductions in carbon fixation over the exposure periods. Although reductions in effective quantum yields were not as great in the $1.0 \mathrm{\mu g} \mathrm{l}^{-1}$ diuron treatment (yields were reduced to $67 \%$ of control values for A. valida and $80 \%$ of controls for A. tenuis and P. damicornis), they were also likely to have affected carbon fixation. Previous studies have documented similar rapid decreases in $\Delta F / F_{\mathrm{m}}{ }^{\prime}$ values for adult (Jones \& Kerswell 2003) and juvenile (Negri et al. 2005) corals exposed to low $\left(1.0 \mathrm{\mu g} \mathrm{l}^{-1}\right)$ and moderate $\left(10 \mu \mathrm{g} \mathrm{l}^{-1}\right)$ concentrations of diuron, although exposure periods were much shorter (a few days). Partial compensation for chronic photoinhibition at PSII by state transitions may allow a switch from linear (electrons flow in series from PSII into PSI) to cyclic electron flow around PSI that is independent of electron transport from PSII (Finazzi \& Forti 2004). However, since there is good quantitative agreement between the reduction in photosynthetic efficiency at $10 \mathrm{\mu g} \mathrm{l}^{-1}$ (Jones et al. 2003) and reduced fixation of carbon within isolated Symbiodinium spp. (Owen et al. 2003), it is more likely that photoinhibition in PSII reduces carbohydrate synthesis (hence energy from photosynthates available to the host) in a relatively direct manner.

Significant decreases in maximum quantum yields $\left(F_{\mathrm{v}} / F_{\mathrm{m}}\right)$ compared to controls for all 3 species in the presence of diuron indicate chronic photoinhibition resulting from secondary damage to the PSII reaction centres (Osmond et al. 1999). The largest reductions in $F_{\mathrm{v}} / F_{\mathrm{m}}$ (by $42 \%$ ) were observed for Pocillopora damicornis in the $10 \mathrm{~g} \mathrm{l}^{-1}$ diuron treatment and concomitantly, this species suffered the most extensive bleaching (loss of pigments or symbionts). In contrast, mean $F_{\mathrm{v}} / F_{\mathrm{m}}$ for Acropora tenuis was reduced by only $15 \%$ compared to controls, and colonies did not bleach, further indicating that chronic photoinhibition was not as severe for this species. A. valida exhibited intermediate $(21 \%)$ declines in $F_{\mathrm{v}} / F_{\mathrm{m}}$ and in some cases host mortality followed. Chronic photoinhibition is a long-lasting process caused by the degradation and reduced turnover of the reaction centre D1 protein because the binding of diuron inhibits the synthesis of proteins (Arg238) specifically associated with the herbicide binding niche of the PSII (Oettmeier 1992, Osmond et al. 1999, Jones 2004). Chronic photoinhibition leads to bleaching, as was observed for both P. damicornis and A. valida in the present study, either because of dissociation of the coral-algal symbiotic relationship and/or reductions in photosynthetic pigment content. Although A. tenuis exposed to $10 \mathrm{\mu g} \mathrm{l}^{-1}$ diuron suffered chronic photoinhibition, its symbiosis with Symbiodinium remained intact, suggesting that this partnership is the most resistant of the 3 species examined.

Reduced photosynthetic efficiency as a result of diuron exposure is likely to constitute a major energy constraint for corals, because the algal partner translocates up to $95 \%$ of its photosynthates (carbohydrates) to the coral host (Muscatine et al. 1984). Owen et al. (2003) demonstrated that exposure of Symbiodinium spp. to $10 \mathrm{\mu g} \mathrm{l}^{-1}$ diuron reduces photosynthetic carbon fixation by 60 to $70 \%$. In our experiments, exposure of Acropora valida to $10 \mathrm{\mu g} \mathrm{l}^{-1}$ diuron resulted in an $85 \%$ reduction in polyp fecundity. Although the sizes of remaining eggs did not differ from those of controls, the corals were unable to spawn, possibly because the eggs were not fully mature. Reductions in the number rather than the size of eggs suggest that $A$. valida may have reabsorbed some oocytes to counter energy deficiencies. Michalek-Wagner \& Willis (2001) also reported that colonies of the soft coral Lobophytum compactum that had been moderately bleached midway through their oogenic cycle contained nearly $45 \%$ fewer mature eggs per polyp than non-bleached colonies as a result of nutritional limitations from the loss of photosynthetic symbionts. This strategy of sacrificing egg numbers to enable the development of a few viable eggs may be common among stressed corals (Yamazato et al. 1981, Michalek-Wagner \& Willis 2001). In the brooding coral Pocillopora damicornis, normal-sized planulae were observed within dissected polyps and larvae were successfully released during the first planulation event. Normal-sized planulae were also observed within the dissected polyps of the 
severely bleached $P$. damicornis colonies exposed to $10 \mathrm{\mu g} \mathrm{l}^{-1}$ diuron (Fig. 4D); however, these larvae were not released during the second planulation event. Energy deficiencies experienced by $P$. damicornis resulting from reduced photosynthetic production are likely to have interfered with the development of larvae, potentially inhibiting or delaying their release. Although it is possible that diuron has a direct nontarget effect on unknown biochemical pathways of the coral host, there is currently no biochemical evidence of direct diuron toxicity on invertebrates at the low to moderate concentrations used in the present study. Furthermore, the lack of impact of high $\left(100 \mu \mathrm{g} \mathrm{l}^{-1}\right)$ concentrations of diuron on the fertilisation, metamorphosis and health of juvenile corals during their aposymbiotic life history stages (Negri et al. 2005, Watanabe et al. 2006) supports this interpretation. A. valida and $P$. damicornis appear to be highly dependent on energy from photosynthesis for reproduction. Under the conditions of severe photoinhibition caused by diuron, these corals are likely to have preferentially allocated energy towards critical metabolic activities at the expense of reproduction.

In contrast to the decreased reproductive output found for Acropora valida and Pocillopora damicornis exposed to diuron, reductions in the numbers of eggs were not observed in A. tenuis. Furthermore, A. tenuis colonies exposed to $10 \mu \mathrm{g} \mathrm{l}^{-1}$ diuron successfully spawned, indicating that diuron-induced photoinhibition did not negatively impact on reproductive development in this species. It is possible that $A$. tenuis may not be as dependent on autotrophy as $A$. valida and $P$. damicornis, potentially countering deficiencies in energy from photosynthates (induced by extended periods of photoinhibition) through heterotrophic feeding (Anthony \& Fabricius 2000, Anthony 2006). Heterotrophy could have involved plankton, suspended particulate matter or detritus in the experimental treatments, and corals are known to vary in their ability to utilise heterotrophic feeding to enhance tissue growth (Anthony \& Fabricius 2000). Thus, there is likely to be variation in the impacts of photoinhibition according to a species' ability to increase energy acquisition from heterotrophy to offset reductions in photosynthetic carbohydrates. It is also possible that the 2 to $4 \mathrm{wk}$ longer periods of exposure to diuron experienced by the other 2 species may correspond to a minimum period of photoinhibition required to produce an impact on reproduction. However, A. tenuis did suffer significant photoinhibition throughout most of spermatogenesis, yet spawning was not inhibited. Moreover, A. tenuis was exposed to the diuron treatments for 1.5 wk longer than the 6 wk period that resulted in bleaching in $A$. valida. In combination, these results suggest that $A$. tenuis may be better able to meet its nutritional requirements from other sources. Alternatively, some of the variation in diuron-induced photoinhibition among the 3 study species could be related to differences in energy translocated from the Symbiodinium clades they host. A. tenuis predominantly hosts Clade C1 (van Oppen et al. 2001), whereas A. valida harbours a mix of both Clades D and $\mathrm{C}$ at the Magnetic Island site where experimental colonies were collected (Ulstrup \& van Oppen 2003). Little et al. (2004) demonstrated that genetically distinct Symbiodinium spp. provide differential benefits to the physiological performance of the coral host, as shown by 2-fold greater growth rates of juvenile Acropora spp. hosting Clade C compared to Clade D. Carbon fixation experiments comparing the translocation of radiolabelled photosynthates into the tissues of corals hosting different Symbiodinium types provide a promising model for exploring the physiological links between the symbiont and the coral host, and would help to unravel the differing species-level responses to diuron found in the present study. Such studies would also help to further validate postulated links between chronic diuron-induced photoinhibition (this paper), reduced photosynthate production in Symbiodinium spp. (Owen et al. 2003) and predicted reductions in photosynthate transfer to the host, which best explain the reduced reproductive investment and success observed in this study.

The significant reductions in total lipid prior to reproductive events involving the release of eggs or larvae in all corals exposed to $10 \mu \mathrm{g} \mathrm{l}^{-1}$ diuron indicate that moderate levels of diuron reduce lipid synthesis. Moreover, the reduced lipid content of Acropora valida prior to spawning in the $1.0 \mathrm{\mu g} \mathrm{l}^{-1}$ treatment indicates that even low concentrations of diuron can have an impact on lipid synthesis. Protein synthesis is dependent upon heterotrophy for nitrogen and phosphorus sources, whereas lipid synthesis is primarily stimulated by light and carbon from photosynthesis (Crossland et al. 1980, Anthony \& Fabricius 2000). Therefore, reductions in total lipid in elevated diuron treatments prior to spawning or planulation suggest that this herbicide reduced energy reserves available for investment into reproduction as a result of diminished photosynthetic productivity. The reductions in mean lipid content between samples collected immediately before and after spawning (reductions of $40 \%$ for $A$. tenuis field control and $66 \%$ for A. valida tank controls) are consistent with the release of eggs during spawning (cf. the $70 \%$ reduction in the overall lipid content of $A$. tenuis tissues due to spawning; Leuzinger et al. 2003). The lack of a significant decline in lipid content in Pocillopora damicornis after planulation may reflect the low proportion of polyps that contained planulae, with these low numbers making an insignificant contribu- 
tion to total lipids in comparison to the high lipid content of coral somatic tissue (Stimson 1987, Ward 1995a). Nevertheless, the reduced lipid content of all 3 species exposed to $10 \mu \mathrm{g} \mathrm{l}^{-1}$ diuron indicates that deficiencies in stored energy reserves occurred for each of the species tested. Energy deficiencies are interpreted as being greatest for $A$. valida and $P$. damicornis in accordance with the greater reductions in the number of eggs and larvae found for these 2 species.

The relative concentrations of xanthophyll carotenoids, diadinoxanthin and diatoxanthin, were of particular interest in this study because of their potential to protect photosynthetic cells from damage created by diuron-induced photoinhibition. PSII herbicides such as diuron cause a build up of electrons within PSII, and the resulting triplet chlorophyll state $\left({ }^{3} \mathrm{chl}\right)$ can lead to the formation of free radicals and toxic oxygen species that can destroy the integrity of chlorophylls, disconnecting them from the antennae systems and protective carotenoids, thus further reducing the ability of symbiotic algae to capture light and produce carbohydrates (Osmond et al. 1999, Jones 2004). In light reactions, the xanthophyll cycle functions photoprotectively by converting diadinoxanthin to diatoxanthin, which dissipates excess absorbed light energy as heat (Ambarsari et al. 1997, Brown et al. 1999). In the present study, the ratio of diatoxanthin:diadinoxanthin was consistently low, even in bleached colonies of Acropora valida in the $10 \mu \mathrm{g} \mathrm{l}^{-1}$ diuron treatment. This indicates that either the conversion of diatoxanthin back to the protective diadinoxanthin was rapid or light levels (Ambarsari et al. 1997) and diuron-induced photoinhibition (Jones \& Kerswell 2003) were not severe enough to significantly affect the balance within the xanthophyll pool. There was also no apparent increase in peridinin, the light-harvesting carotenoid that may be used to offset decreases in chl $a$ and $c_{2}$ as a strategy to maintain photosystem efficiency under oxidative stress. The consistent pigment ratios across all treatments indicate that any loss of pigmentation in the $10 \mu \mathrm{g} \mathrm{l}^{-1}$ diuron treatments was not likely to have resulted from pigment degradation but was instead related to expulsion of complete algal cells (Fig. 5).

In summary, all 3 coral species displayed significant and consistent reductions in photosynthetic efficiency and total lipid content when subjected to long-term diuron exposures. The species Acropora valida and Pocillopora damicornis were most affected, exhibiting severe bleaching, diminished concentrations of photosynthetic pigments ( $A$. valida) and decreased reproductive output. It is important to consider that additional stressors, such as increased turbidity, often accompany elevated herbicide and pesticide contamination in runoff events, potentially adding to pressures on coral photosynthesis (Fabricius 2005, Harrington et al. 2005). Our results, that herbicide-induced chronic photoinhibition and reduced symbiont densities decrease the amount of energy available for reproduction and can inhibit reproductive output completely, highlight the importance of photosynthesis for coral reproduction. We conclude that elevated levels of diuron, at concentrations as low as $1 \mu \mathrm{g} \mathrm{l}^{-1}$ and sustained throughout gametogenesis, are likely to reduce the replenishment of nearshore coral populations for corals that are highly dependent upon energy derived from photosynthesis.

Acknowledgements. This study was supported by the AIMS@JCU scholarship scheme. We thank M. Weirer, K. Markey, G. Eaglesham C. Bennett, K. Dabinett, T. Phillips, C. Humphrey and H. Boyett for their assistance with laboratory analyses and fieldwork and A. Baird for comments on this manuscript.

\section{LITERATURE CITED}

Ambarsari I, Brown BE, Barlow RG, Britton G, Cummings D (1997) Fluctuations in algal chlorophyll and carotenoid pigments during solar bleaching in the coral Goniastrea aspera at Phuket, Thailand. Mar Ecol Prog Ser 159: 303-307

Anthony KRN (2006) Enhanced energy status of corals on coastal, high-turbidity reefs. Mar Ecol Prog Ser 319:111-116

Anthony KRN, Fabricius KE (2000) Shifting roles of heterotrophy and autotrophy in coral energetics under varying turbidity. J Exp Mar Biol Ecol 252:221-253

Arai T, Kato M, Heyward AJ, Ikeda Y, Iizuka T, Maruyama T (1993) Lipid composition of positively buoyant eggs of reef building corals. Coral Reefs 12:71-75

Brown BE, Ambarsari I, Warner ME, Fitt WK, Dunne RP, Gibb SW, Cummings DG (1999) Diurnal changes in photochemical efficiency and xanthophyll concentrations in shallow water reef corals: evidence for photoinhibition and photoprotection. Coral Reefs 18:99-105

Crossland CJ, Barnes DJ, Borowitzka MA (1980) Diurnal lipid and mucus production in the staghorn coral Acropora acuminata. Mar Biol 60:81-90

Edmunds PJ, Gates RD (2002) Normalizing physiological data for scleractinian corals. Coral Reefs 21:193-197

Fabricius KE (2005) Effects of terrestrial runoff on the ecology of corals and coral reefs: review and synthesis. Mar Pollut Bull 50:125-146

Finazzi G, Forti G (2004) Metabolic flexibility of the green alga Chlamydomonas reinhardtii as revealed by the link between state transitions and cyclic electron flow. Photosynth Res 82:327-338

Hamilton D, Haydon G (1996) Pesticides and fertilisers in the Queensland Sugar Industry-estimates of usage and likely environmental fate. Department of Primary Industries, Brisbane

Harrington L, Fabricius K, Eaglesham G, Negri A (2005) Synergistic effects of diuron and sedimentation on photosynthesis and survival of crustose coralline algae. Mar Pollut Bull 51:415-427

Harrison PL, Wallace CC (1990) Reproduction, dispersal and recruitment of scleractinian corals. In: Dubinsky Z (ed) Coral reefs. Ecosystems of the world, Vol 25. Elsevier, New York, p 133-207 
Haynes D, Muller J, Carter S (2000) Pesticide and herbicide residues in sediments and seagrasses from the Great Barrier Reef world heritage area and Queensland coast. Mar Pollut Bull 41:279-287

Jones RJ (2004) Testing the 'photoinhibition' model of coral bleaching using chemical inhibitors. Mar Ecol Prog Ser 284:133-145

Jones RJ (2005) The ecotoxicological effects of Photosysem II herbicides on corals. Mar Pollut Bull 51:495-506

Jones RJ, Kerswell AP (2003) Phytotoxicity of Photosystem II (PSII) herbicides to coral. Mar Ecol Prog Ser 261:149-159

Jones RJ, Muller J, Haynes D, Schreiber U (2003) Effects of herbicides diuron and atrazine on corals of the Great Barrier Reef, Australia. Mar Ecol Prog Ser 251:153-167

Leuzinger S, Anthony KRN, Willis BL (2003) Reproductive energy investment in corals: scaling with module size. Oecologia 136:524-531

Little AF, van Oppen MJH, Willis BL (2004) Flexibility in algal endosymbioses shapes growth in reef corals. Science 304: $1492-1494$

Loya Y, Lubinevsky H, Rosenfeld M, Kramarsky-Winter E (2004) Nutrient enrichment caused by in situ fish farms at Eilat, Red Sea is detrimental to coral reproduction. Mar Pollut Bull 49:344-353

Markey KL, Baird AH, Humphrey C, Negri AP (2007) Insecticides and a fungicide affect multiple coral life stages. Mar Ecol Prog Ser 330:127-137

Maxwell K, Johnson GN (2000) Chlorophyll fluorescence-a practical guide. J Exp Bot 51:659-668

Michalek-Wagner K, Willis BL (2001) Impacts of bleaching on the soft coral Lobophytum compactum. I. Fecundity, fertilization and offspring viability. Coral Reefs 19: 231-239

Mitchell C, Brodie J, White I (2005) Sediments, nutrients and pesticide residues in event flow conditions in streams of the Mackay Whitsunday Region, Australia. Mar Pollut Bull 51:23-36

Muscatine L, Falkowski PG, Porter JW, Dubinsky Z (1984) Fate of photosynthetic fixed carbon in light and shadeadapted colonies of the symbiotic coral Stylophora pistillata. Proc R Soc Ser B 222:181-202

Negri AP, Vollhardt C, Humphrey C, Heyward AJ, Jones RJ, Eaglesham G, Fabricius KE (2005) Effects of the herbicide diuron on the early life history stages of coral. Mar Pollut Bull 51:370-383

Oettmeier W (1992) Herbicides of photosystem II. In: Barber J (ed) The photosystems: structure, function and molecular biology, Vol 11. Elsevier, Amsterdam, p 349-408

Osmond CB, Anderson JM, Ball MC, Egerton JJG (1999) Compromising efficiency: the molecular ecology of light resource utilisation in terrestrial plants. In: Scholes C, Baker M (eds) Advances in physiological plant ecology. Blackwell, Oxford, p 1-24

Owen R, Knap A, Ostrander N, Carbery K (2003) Compara-

Editorial responsibility: Otto Kinne (Editor-in-Chief), Oldendorf/Luhe, Germany tive acute toxicity of herbicides to photosynthesis of coral zooxanthellae. Bull Environ Contam Toxicol 70:541-548

Richmond RH (1987) Energetic relationships and biogeographical differences among fecundity, growth and reproduction in the reef coral Pocillopora damicornis. Bull Mar Sci 41:594-604

Rinkevich B (1989) The contribution of photosynthetic products to coral reproduction. Mar Biol 101:259-263

Simpson BW (2002) Water quality in the Pioneer Catchment on February $14-15,2002$. Water quality assessment and protection. Natural Resource Sciences, Natural Resources and Mines, Queensland, Indooroopilly

Stearns SC (1992) The evolution of life histories. Oxford University Press, Oxford

Stimson JS (1987) Location, quantity and rate of change in quantity of lipids in tissue of Hawaiian hermatiypic corals. Bull Mar Sci 41:889-904

Szmant-Froelich A (1981) Coral nutrition: comparison of the fate of ${ }^{14} \mathrm{C}$ from ingested labelled brine shrimp and from the uptake of $\mathrm{NaH}^{14} \mathrm{CO}_{3}$ by its zooxanthellae. J Exp Mar Biol Ecol 55:133-144

Szmant AM, Gassman NJ (1990) The effects of prolonged 'bleaching' on the tissue biomass and reproduction of the reef coral Montastrea annularis. Coral Reefs 8:217

Ulstrup KE, van Oppen MJH (2003) Geographic and habitat partitioning of genetically distinct zooxanthellae (Symbiodinium) in Acropora corals on the Great Barrier Reef. Mol Ecol 12:3477-3484

van Oppen MJH, Palstra FP, Piquet AMT, Miller D (2001) Patterns of coral-dinoflagellate associations in Acropora: significance of local availability and physiology of Symbiodinium strains and host-symbiont selectivity. Proc R Soc Ser B 268:1759-1767

Ward S (1995a) The effect of damage on the growth, reproduction and storage of lipids in the scleractinian coral Pocillopora damicornis (Linnaeus). J Exp Mar Biol Ecol 187:193-206

Ward S (1995b) Two patterns of energy allocation for growth, reproduction and lipid storage in the scleractinian coral Pocillopora damicornis. Coral Reefs 14:87-90

Watanabe T, Yuyama I, Yasumura S (2006) Toxicological effects of biocides on symbiotic and aposymbiotic juveniles of the hermatypic coral Acropora tenuis. J Exp Mar Biol Ecol 339:177-188

Wright SW, Jeffrey SW (1997) High-resolution HPLC system for chlorophylls and carotenoids of marine phytoplankton. In: Jeffrey SW, Mantoura RFC, Wright SW (eds) Phytoplankton pigments in oceanography: guidelines to modern methods. UNESCO, Paris, p 327-341

Yamazato K, Sato M, Yamashiro H (1981) Reproductive biology of an alcyonacean coral Lobophytum crassum Marenzeller. Proc 4th Int Coral Reef Symp 2:671-678

Zar JH (1996) Biostatistical analysis. Prentice Hall, Englewood Cliffs, NJ

Submitted: September 18, 2006; Accepted: May 22, 2007

Proofs received from author(s): August 9, 2007 